\title{
Efficacy of Miltefosine and Artemether on infected Biomphalaria alexandrina snails with Schistosoma mansoni: immunological and histological studies
}

\author{
H. H. ABDEL-AZEEM ${ }^{1}$, G. Y. OSMAN ${ }^{1}$, M. F. EL GARHY ${ }^{2}$, K. S. AL BENASY ${ }^{1,3, *}$ \\ 'Department of Zoology, Menoufia University, Shebeen El-koom, Egypt; ' 2 Department of Zoology, Cairo University, Giza, Egypt; \\ ${ }^{3,{ }^{*}}$ College of Applied Medical Sciences, Majmaah University, Saudi Arabia, E-mail: K.albenasy@mu.edu.sa
}

Article info

Received May 8, 2020

Accepted July 8, 2020

\section{Summary}

Biomphalaria alexandrina snails have received much attention due to their great medical importance as vectors for transmitting Schistosoma mansoni infection to humans. The main objective of the present work was to assess the efficacy of miltefosin a synthetic molluscicidal drug and artemether a natural molluscicidal drug. The correlation between immunological and histological observations from light and electron microscopy of the hemocytes of $B$. alexandrina post treatment with both drugs was also evaluated. $\mathrm{LC}_{50}$ and $\mathrm{LC}_{90}$ values were represented by $13.80 \mathrm{ppm}$ and $24.40 \mathrm{ppm}$ for miltefosine and $16.88 \mathrm{ppm}$ and $27.97 \mathrm{ppm}$ for artemether, respectively. The results showed that the treatment of $S$. mansoni-infected snails and normal snails with sublethal dose of miltefosine $\left(\mathrm{LC}_{25} 8.20 \mathrm{ppm}\right)$ and artemether $\left(\mathrm{LC}_{25=} 11.04 \mathrm{ppm}\right)$ induced morphological abnormalities and a significant reduction in hemocytes count.

Keywords: Biomphalaria alexandrina; miltefosine; artemether; hemocytes; immunological and histological studies; light and electron microscope

\section{Introduction}

Schistosomiasis represents a global health concern with over 700 million people at risk of contracting this disease (Weber et al., 2019). In Egypt eradicating this disease is a top governmental priority (Abou-El-Naga, 2018).

Generally, chemotherapy is still one of the most effective methods for controlling Schistosoma infection (Bertão et al., 2012a). Since the mid-1970's, PZQ (praziquantel derivatives) represented the anti-helminthic drug of choice. Despite its efficiency in reducing morbidity and mortality rates in Schistosoma infections (Caffrey, 2007), it is not active against early stages of schistosomes and causes species resistance (Bertão et al., 2012b). Currently, miltefosine and artemether (antimalarial drugs) have a potential application in schistosomiasis treatment (El Beshbishi et al.,2018).
Miltefosine (hexadecylphosphocholine) is an alkyl phospholipid derivative that was developed as a new type of antitumor agent in the 1990s (Eibla and Unger, 1990). Miltefosine has comparative advantage over PZQ as antischistomicidal drug due to its efficacy on the differential developmental stages of $S$. mansoni in infected mice (Eissa et al., 2011). Miltefosine used as an schistosomicidal drug increased helminths mortality rate and induced extensive tegumental changes in the adult worms of Egyptian and Brazilian strains of S. mansoni in vitro and in vivo (Eissa et al., 2015; El-Faham et al., 2017). In addition, miltefosine presents a molluscicidal activity against both Biomphalaria alexandrina and Bulinus truncatus snails (Eissa et al., 2011). Artemether is a methyl ether derivative of artemisinin, a compound extracted from the leaves of the Chinese wormwood plant (Artemisia annua) (Mossalem et al., 2013). It was first described as anti-schistosomal agent in

\footnotetext{
* - corresponding author
} 
1980s, against juvenile worms (5-21day-old) S. japonicum (Liu et al., 2012). Artemether efficiency as a schistosomicidal and molluscicidal agent has been previously shown (Al-Kazzaz et al., 2014; Madbouly et al.,2015).

The aims of this work were to compare the efficacy of miltefosine, a chemotherapeutic synthetic compound, with artemether, a natural molluscicidal through light and electronic microscopy and to elucidate their effect on normal immune-histological parameters in S. mansoni-infected $B$. alexandrina snails.

\section{Materials and Methods}

\section{Experimental snails}

B. alexandrina snails (8-10 $\mathrm{mm}$ in diameter) were obtained from Schistosoma Biological Supply Centre at the Medical Malacology Laboratory, Theodor Bilharz Research Institute, Giza, Egypt. The snails were classified as follows:

- Group (1): 50 normal control snails (unexposed snails).

- Group (2): 100 normal snails divided into two subgroups (per 50 snails) exposed to sublethal concentrations $L C_{25}$ of miltefosine and artemether for 2 successive week intervals in two replicates for each drug.

- Group (3):150 snails were exposed to Schistosoma mansoni miracida with a dose of 10 per snail (Liang et al., 1987). This group was further divided into 3 subgroups;

- Group (3a): 50 infected snails

- Group (3b): 50 infected snails treated with a sublethal concentration $\mathrm{LC}_{25}$ of miltefosine for 2 successive weeks in two replicates for each drug.

- Group (3c): 50 infected snails treated with a sublethal concentration $\mathrm{LC}_{25}$ of artemether for 2 successive weeks in two replicates for each drug.

For each drug, the treatment was changed weekly with freshly prepared one to avoid the effect of storage. The snails were exposed to the tested concentrations for 2 successive weeks, then removed from the experimental environment, washed thoroughly with dechlorinated tap water and washed the one time only (after first 24 hours) to recover.

\section{Experimental materials}

1 - The drug miltefosine (100 $\mathrm{mg}$ ) was provided by (Sigma-Aldrich Chemie and GmbH, CA 58066-85-6, MW 407.57, Germany) and its trade name is Impavido (molar mass $407.568 \mathrm{~g} / \mathrm{mol}$, chemical formula $\mathrm{C}_{21} \mathrm{H}_{46} \mathrm{NO}_{4} \mathrm{P}$ ).

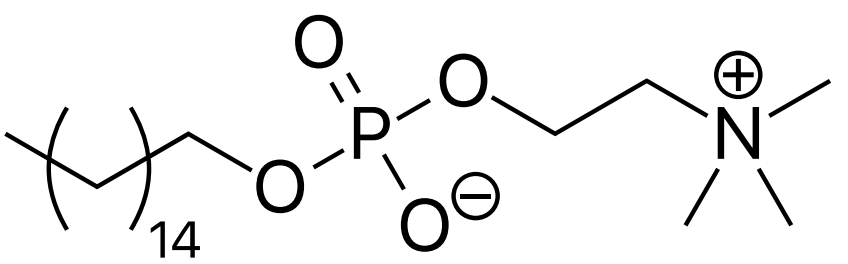

Miltefosine structure
2 - The drug artemether was obtained in the form of tablets (Kunming Pharmaceutical Cooperation, PR China) with a documented purity of $99.6 \%$. It is sold under the trade name Riamet and Coartem among others, has a molar mass of $298.374 \mathrm{~g} / \mathrm{mol}$ and the chemical formula is $\mathrm{C}_{16} \mathrm{H}_{26} \mathrm{O}_{5}$. The actual concentration was calculated as the percentage of the active material in the used weight. Artemether was applied to snails as aqueous solution of tablets.

\section{Artemether structure}

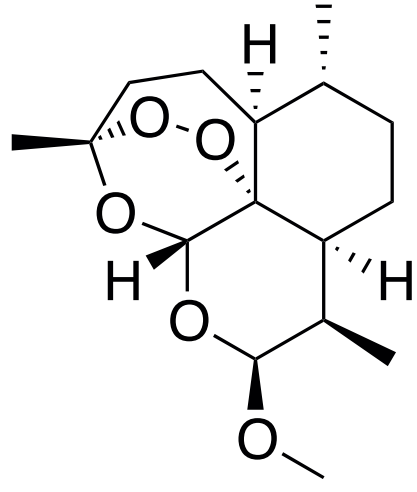

Molluscicidal properties of miltefosine and artemether drugs A stock solution of $1000 \mathrm{ppm}$ from each drug was prepared on the basis of weight/volume using dechlorinated water. A series of concentrations was prepared for each drug according to the standard procedure recommended by $\mathrm{WHO}$ (1965) that allowed us to reach experimental concentrations $\left(\mathrm{LC}_{0}, \mathrm{LC}_{10}, \mathrm{LC}_{25}, \mathrm{LC}_{50}\right.$ and $\left.\mathrm{LC}_{90}\right)$. The effectiveness of each drug as a molluscicide has been expressed in terms of $\mathrm{LC}_{50}$ and $\mathrm{LC}_{90}$ according to the procedure of Litchfield \& Wilcoxon (1949). Three replicates of gradual concentrations from each stock solution were prepared. The snails were exposed to the tested concentrations for 24 hours, then removed from the experimental environment, washed thoroughly with dechlorinated tap water and transferred to aquaria with fresh dechlorinated tap water for the next 24 hours to recover $\left(25 \pm 2{ }^{\circ} \mathrm{C}\right)$. Unexposed snails (controls) were assayed side by side with the treated groups under the same laboratory conditions in dechlorinated tap water (WHO,1965). Dead snails were noticed and removed from the container.

Immunological and histological study of B. alexandrina hemocytes Hemolymph samples from snails from all studied groups were collected as previously described by Michelson (1966) by removing a small portion of the shell and inserting a capillary tube into the heart. The hemolymph was collected in a vial tube $(1.5 \mathrm{ml})$ and kept in ice-box The collected hemolymph from infected snails and infected treated groups was used to estimate the total hemocytes count using a Bürker- Turk hemocytometer (while the differential haemocyte count was obtained according to a previously published method (Van der knap et al., 1981).While the differential haemocyte count was obtained on the light microscopy level, hemolymph samples were placed individually onto a clean glass slide. Hemocytes were fixed in $100 \%$ methanol, then stained 
Table 1. Molluscicidal activity of miltefosine and artemether against adult $B$. alexandrina snails (24 hours exposure).

\begin{tabular}{lcccccc}
\hline Tested drug & $\begin{array}{c}\mathrm{LC}_{0} \\
\mathrm{Ppm}\end{array}$ & $\begin{array}{c}\mathrm{LC}_{10} \\
\mathrm{Ppm}\end{array}$ & $\begin{array}{c}\mathrm{LC}_{25} \\
\mathrm{ppm}\end{array}$ & $\begin{array}{l}\mathrm{LC}_{50} \\
\mathrm{ppm}\end{array}$ & $\begin{array}{c}\mathrm{LC}_{90} \\
\mathrm{ppm}\end{array}$ & Slope \\
\hline Miltefosine & 1.38 & 3.16 & 8.20 & 13.80 & 24.40 & 1.60 \\
Artemether & 1.68 & 5.79 & 11.04 & 16.88 & 27.97 & 1.75 \\
\hline
\end{tabular}

with Giemsa's stain examined and counted then photographed using Agfa film according to a previously published method (Abdul-Salam \& Michelson, 1980). The hemolymph samples from normal control snails (group1) and drug exposed snails (group 2) were used for transmission electron microscopy examinations (Grimaud et al., 1980).

\section{Statistical analysis}

The results were analysed statistically using the Statistical Package for Social Science (SPSS version 15 package software). Data were expressed as mean $(M) \pm$ standard deviation (S. D). The data were statistically analysed statistically significant differences between the treated and the control group using "t" test (Goldstein, 1964).

\section{Results}

Molluscicidal activity of miltefosine and artemether against B. alexandrina snails

Bioassay tests results are presented in Table 1, revealing that both compounds has a molluscicidal activity against adult snails. It was noticed that miltefosine showed a marked lethal effect against snails compared to artemether $\left(\mathrm{LC}_{50}\right.$ and $\mathrm{LC}_{90}$ of 16.88 and 27.97 $\mathrm{ppm}$, respectively). Its $\mathrm{LC}_{50}$ and $\mathrm{LC}_{90}$ values were $13.80 \mathrm{ppm}$ and $24.40 \mathrm{ppm}$ with a slope function value of 1.60 . Furthermore, these results demonstrated that the sublethal concentrations $\left(\mathrm{LC}_{0}, \mathrm{LC}_{10}\right.$, $\& \mathrm{LC}_{25}$ ) of miltefosine were lower than the corresponding values of artemether.

Effect of the tested drugs on hemocytes of adult $B$. alexandrina snails

Total number of hemocytes of $B$. alexandrina snails

The recorded data in Figure 1 denoted that the exposure of snails (groups $3 \mathrm{~b} \& 3 \mathrm{c}$ ) to $\mathrm{LC}_{25}$ of miltefosine ( $8.20 \mathrm{ppm}$ ) and artemether (11.04 ppm) for 24 hours for 2 successive weeks exhibited a significant decrease $(P<0.001)$ in hemocytes count compared with the control group (infected snails; group 3a). The reduction in hemocytes was of $65.48 \%$ and $47.62 \%$ in miltefosine and artemether treated groups, respectively

Effect of the tested drugs on percentage of different types of hemocytes

As for the number of the different haemocyte types; the exposure of adult infected snails (groups $3 b \& 3 c$ ) to the $\mathrm{LC}_{25}$ drugs concentrations induced a decrease in hyalinocytes percentage. Miltefosine treated-infected snails had the lowest percentage of hyalinocytes (18.40\%) compared to artemether treated $(26.60 \%)$ and control snails (group3a) (52.3\%) (Figure 2). On the contrary, both drugs induced an elevation in the percentage of small round cells and granulocytes in corresponding to the infected-control group (group3a).

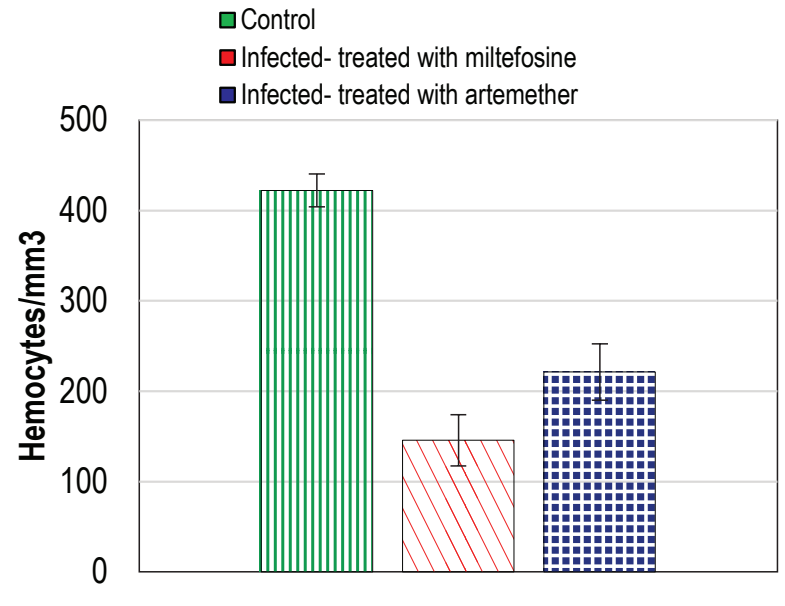

Hemocytes No.

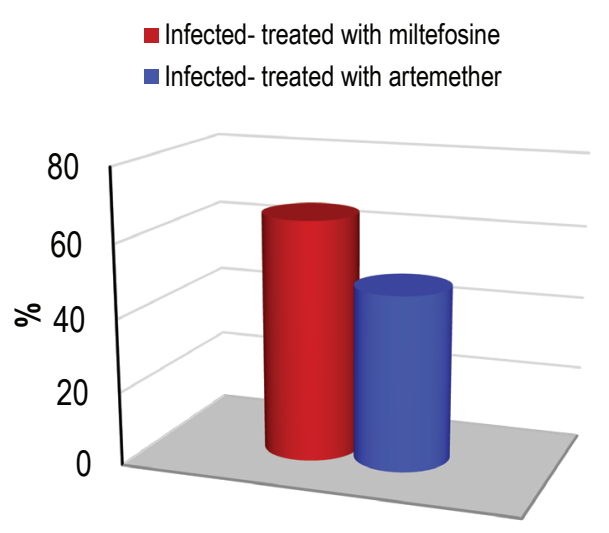

\%Change in Hemocytes No.

Fig. 1. Effect of $\mathrm{LC}_{25}$ of the miltefosine and artemether drugs on hemocytes count adult $B$. alexandrina snails as compared with infected snails (controls) 


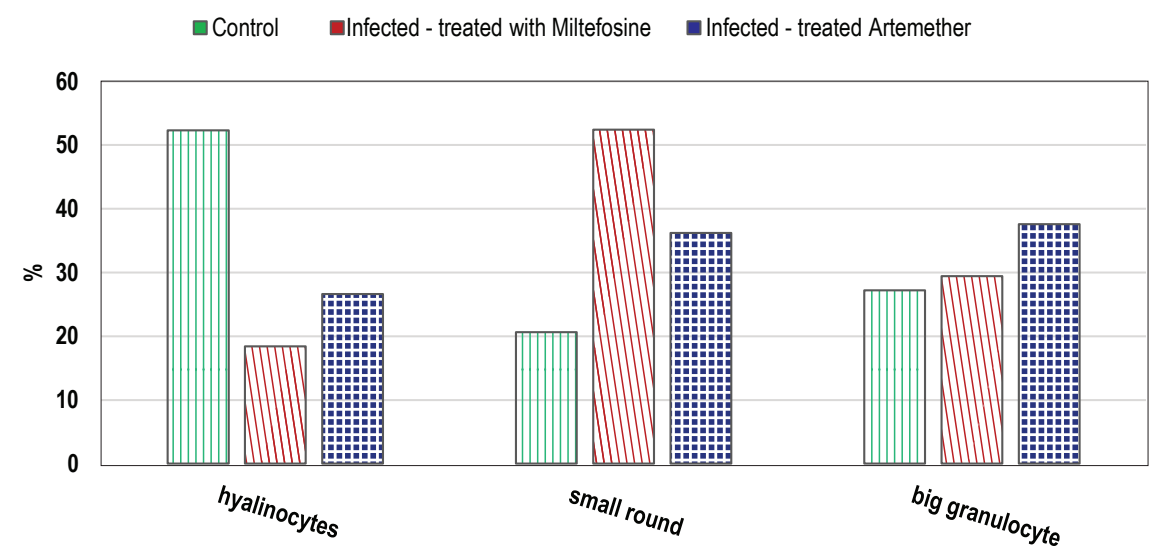

Fig.2: Effect of $\mathrm{LC}_{25}$ of the miltefosine and artemether drugs on \% different hemocytes types in hemolymph of adult $B$. alexandrina snails as compared with infected snails (controls)

Morphological alterations induced by miltefosine and artemether observed in light and electronic microscopy

\section{Light microscope study}

Hemocytes examination of the normal control snails (group1) by light microscopy revealed the presence of three morphologically different cell types (Plate $1 \mathrm{~A}-\mathrm{C}$ ); small undifferentiated cells with a spherical profile $(A)$, large spherical granulocytes with a double membrane and a relatively large cytoplasm filled with a variable number of basophilic granules (B), and polymorphic hyalinocytes with either a large eccentric nucleus or two nuclei, suggesting atypical cell division (C).

The exposure of adult non-infected $B$. alexandrina (group 2) to $\mathrm{LC}_{25}$ miltefosine $(8.20 \mathrm{ppm})$ and artemether $(11.04 \mathrm{ppm})$ for 24 hours for 2 successive weeks induced some alterations on the morphology of granulocytes and hyalinocytes, but small undifferentiated cells were not affected. In drug exposed snails noticed by light microscopy that granulocyte appeared under different sizes granules. Hyalinocytes on the other hand, had a large vacuolated cytoplasm and a shrunk nucleus (Plates $2 \& 3$ ).

\section{Electron microscope study (TEM)}

The ultrastructural examination of normal control hemocytes (group1) showed the presence of three morphologically different cell types (Plate $4 \mathrm{~A}-\mathrm{C}$ ). The exposure of adult snails to sublethal concentrations $\left(\mathrm{LC}_{25}\right)$ of the examined drugs showed a different type of cells with two types of globules in the cytoplasm that appeared only in the hemolymph of treated snails (group 2) (Plate 5 A-C).

Miltefosine treatment induced the following alterations in hemocytes types of non-infected snails (group 2 a): small undifferentiated cells showed a large nucleus, an intact cell membrane, cytoplasmic extensions (pseudopodia), vacuoles, and phagolysosomes in the cytoplasm (5 A); granulocytes presented nucleus with irregular boundaries and an irregular chromatin distribution, the cytoplasm contained phagolysosomes, granules, and some cell organelles such as the mitochondria and rough endoplasmic reticulum (5 B); hyalinocytes presented a degenerated outer cell membrane, the nucleus had an irregular membrane, and the nucleus shrunk in size $(5 \mathrm{C})$.

Artemether induced the following on different types of hemocytes of snails (group 2 b) (Plate 6 A-C): small undifferentiated cells had an intact cellular membrane with extended pseudopodia, the cytoplasm and the nuclei contained phagolysosomes and vacuoles (6 A); granulocytes showed pseudopodia, cytoplasmic granules,
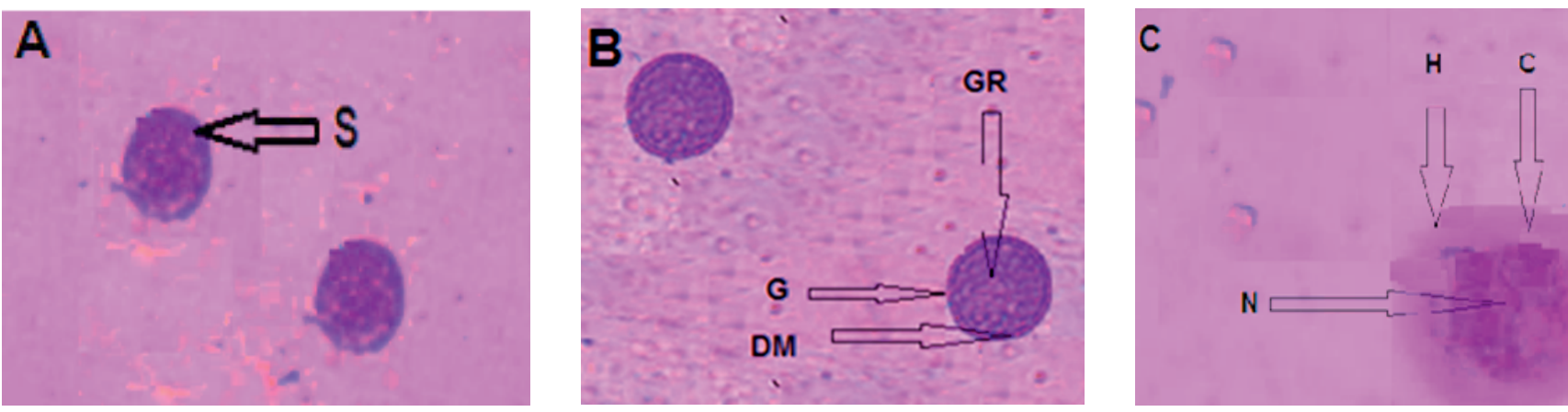

Plate 1. A). Normal round small (non-differentiated) cells B). Granulocyte and C). Hyalinocyte of $B$. alexandrina adult snails (x40). S: Round small cell, G: Granulocyte, C: Cytoplasm, DM: Double membrane, GR: Granules, N: Nucleus, (H): Hyalinocyte. 

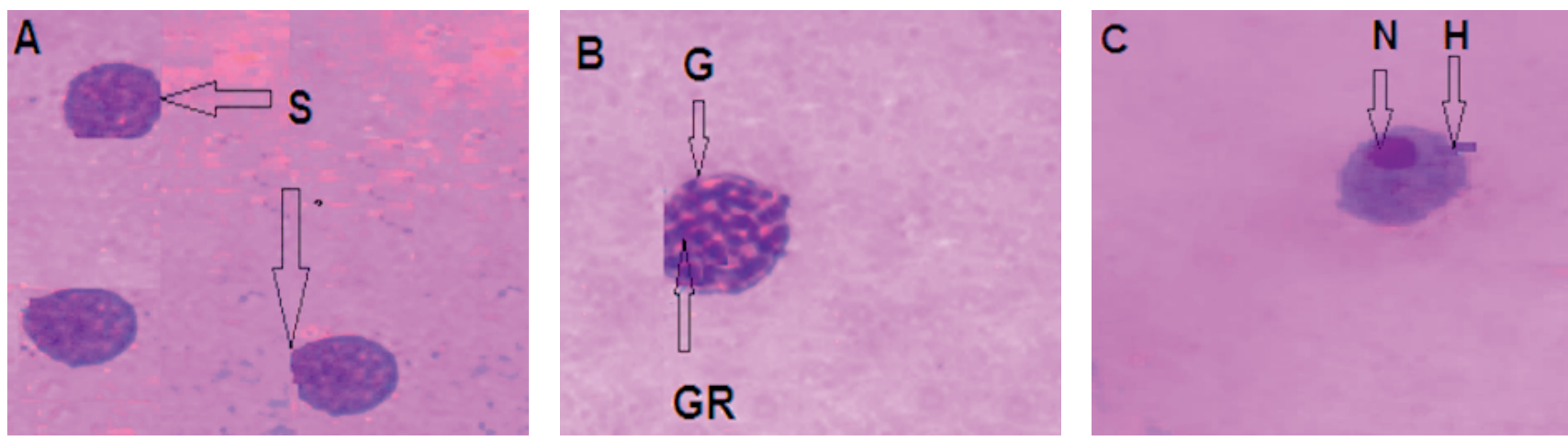

Plate 2. The morphological effect of miltefosine $\mathrm{LC}_{25}$ on different types of hemocytes in the haemolymph of treated-infected $B$. alexandrina snails. A): Round small nondifferentiated cell, B): Granulocyte and C): Hyalinocyte (x40). S: Round small cell, G: Granulocyte, GR: Granules, N: Nucleus, (H): Hyalinocyte.
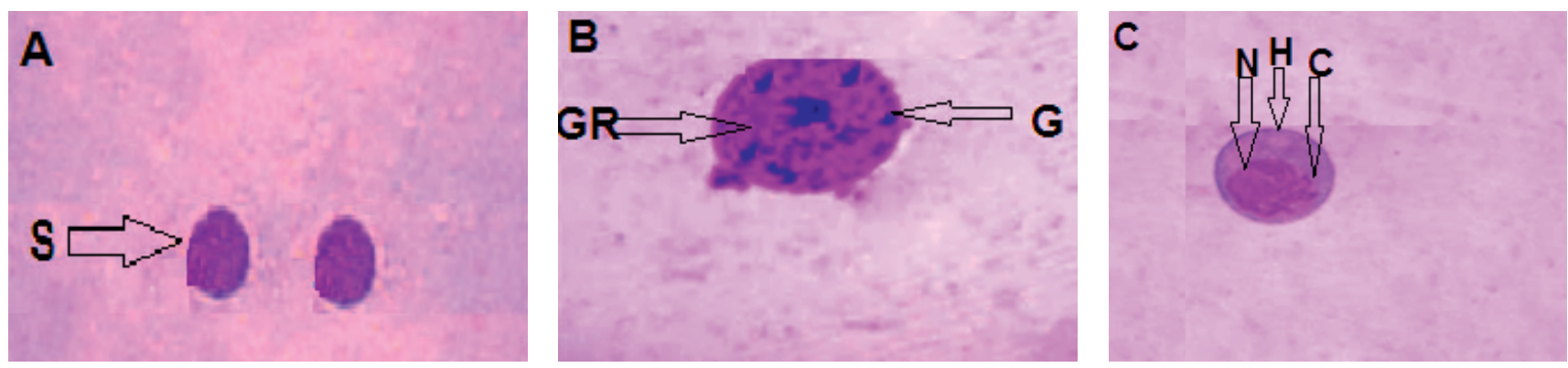

Plate 3. The morphological effect of artemether $\mathrm{LC}_{25}$ on different types of hemocytes in the haemolymph of treated $B$. alexandrina snails. A): Round small (nondifferentiated), B): Granulocyte and C): Hyalinocyte (x40). S: Round small cell, G: Granulocyte, C: Cytoplasm, GR: Granules, N: Nucleus, (H): Hyalinocyte.
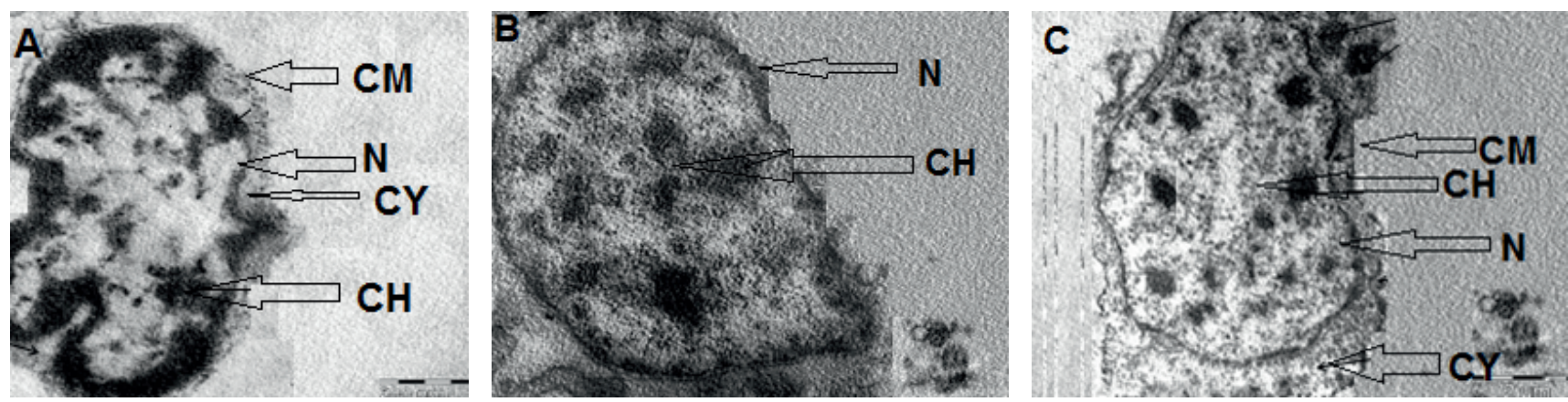

Plate 4. TEM micrographs showing normal cells of $B$. alexandrina snails, A). Round small non- differentiated cell, B). Granulocyte and C). Hyalinocyte. CH: chromatin, CM: cell membrane, CY: Cytoplasm, N: nucleus.
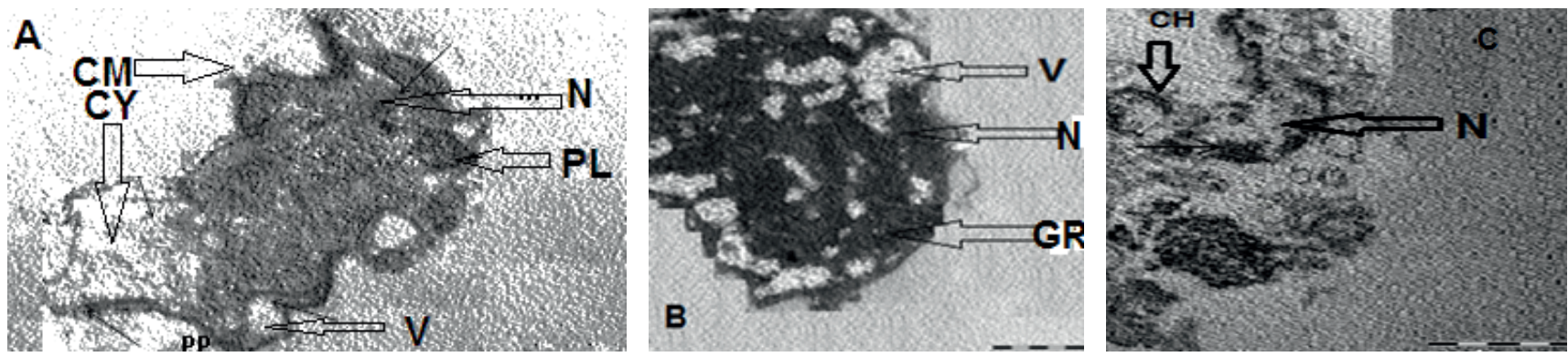

Plate 5. TEM micrographs showing the effect of miltefosine $\mathrm{LC}_{25}$ on hemocytes A). Round small (non- differentiated) cell, B). Granulocyte and C). Hyalinocyte of treatedinfected B. alexandrina snails. CH: chromatin, CM: cell membrane, CY: Cytoplasm, GR: granules, N: nucleus, V: vacuole, PL: phagolysosome. 

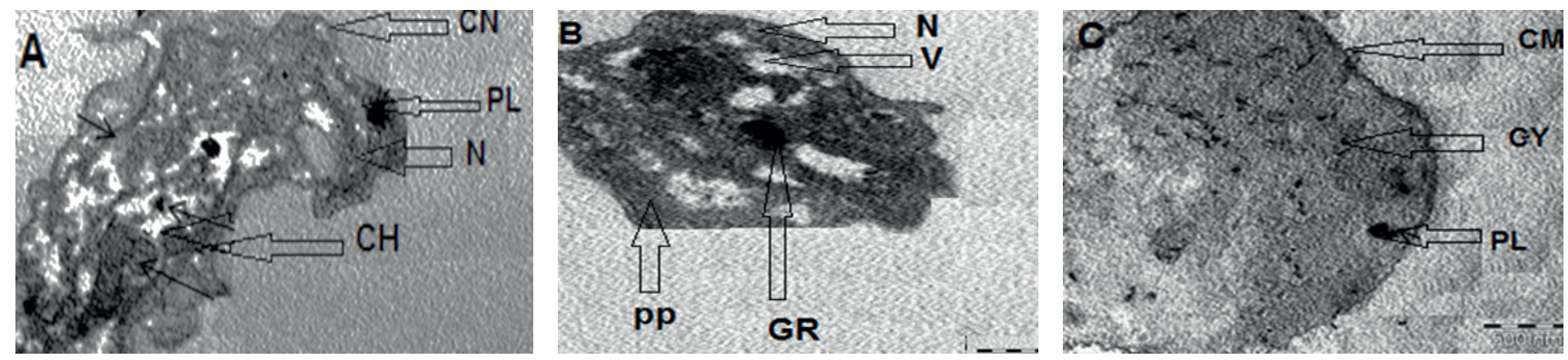

Plate 6. TEM micrographs showing the effect of $\mathrm{LC}_{25}$ artemether drug on hemocytes A). Round small (non- differentiated) cell, B).

Granulocyte and C). Hyalinocyte of treated-infected B. alexandrina snails, CH: chromatin, CM: cell membrane, CY: cytoplasm, GR: granules, V: vacuole, N: nucleus, PL: phagolysosome, PP: pseudopodia.

and vacuoles in cytoplasm (6 B); while hyalinocytes showed an intact cell membrane, degenerated nuclei, and difficult to identify organelles (6 C).

\section{Discussion}

Internal defense mechanisms of invertebrates depend upon an innate immune system including cellular and humoral components (Le Clec'h et al., 2016). Cell-mediated immune response resulted from the presence of various cell categories that are vital in defense and constitute the primary barrier against invading parasites and bacteria as well as accumulate different substances such as molluscicides, heavy metals and pesticides. These are mobile amoeboid cells referred to as amoebocytes or hemocytes (Bernard, 2016). Furthermore, hemocytes of the snail are used to determine the prepatency period of infection with schistosomiasis (Kamel et al. 2006). Previous experimental studies proved that the parasitic infection induced positive effect upon hemocytes count by increasing their number in the hemolymph of various species of snails (Barcante et al., 2012; Mossalem \& Ibrahim, 2019; Suwannatraia et al., 2019).

In the present study, the hemocytes of $S$. mansoni infected snails (had higher significant increase compared to the treated -infected snail groups with the sublethal concentration $\left(\mathrm{LC}_{25}\right)$ of miltefosine and artemether as in previous studies (Mossalem et al., 2013; Ibrahim et al.,2018; Mossalem \& Ibrahim, 2019). The decrease in hemocytes count in treated snail groups might be a result from tissue damage in digestive and hermaphrodite glands as they participated in tissue repair (Esmaeil, 2009). Another explanation might be the reduction in transaminase enzyme activities, sensitive tools in physiological alterations detection (Kamel et al., 2007), or perhaps, it is the result of hemocyte cells from the hemolymph migrating to connective tissues (Cochennec-laureau, 2003).

In regard to the types of hemocytes, the present study detected 3 types of cells in $B$. alexandrina hemolymph; hyalinocytes, small round cells and granulocytes. This finding agrees with the results of other studies (Mohamed et al. ,2006; Cavalcanti et al., 2012). Some authors suggested that the hyalinocytes and the granulocytes are different cell types, while others considered that they represent different developmental phases of the same cell type (Oliveira et al., 2010). Another study revealed that granulocytes were phagocytic cells with pseudopods capable of encapsulating large particles, while the hyalinocytes were spherical smaller cells without pseudopods (Yoshino et al., 2008). Additionally, the present study showed that the percentage of hyalinocytes decreased in both miltefosine and artemether exposed groups, while the percentage of round small cells (undifferentiated cells) and granulocytes increased in exposed groups compared to the normal uninfected control group. The present data are in accordance with Bakry et al. (2012) with a study showing that methanol extracts of Azadirachta indica plant induced a significant increase in the number of granulocytes in the hemolymph of $B$. alexandrina snails indicating a high response of the snails against the treatment. Several studies explained the fluctuations in percentage of the types of hemocytes of aquatic snails as a result of drug treatment (Bakry et al., 2012). A study reported that granular hemocytes were the major responsive hemocytes type in $B$. alexandrina snails treated with a plant growth regulator (Mepiquat chloride) (Mohamed \& Abdel-Gawad, 2005). Another study detected an increase in the percentage of small round undifferentiated cells, which may be due to the stimulation of the hematopoietic organ producing undifferentiated hemocytes that differentiated into granulocytes to compensate their reduction in number (El Sayed, 2006). Furthermore, a study stated that hyalinocytes are thought to be responsible primarily for wound repair requiring aggregation at injury site, thus their number decreased in the hemolymph (Barcante et al., 2012). It was reported that granulocyte cells are immunological active cells found mainly in the hemolymph of snails, instead of remaining in the damaged tissue to face external stimuli (Oliveira et al., 2010)

The ultra-structural observation of hemocytes showed that the tested drugs induced morphological alterations, such as irregular nuclear boundaries, irregular chromatin distribution, degenerated nuclei, and vacuolated cytoplasm with electron-dense phagolysosomes; this is in agreement with the results obtained by others (El Sayed et al., 2011; Ibrahim et al.,2018). Kamel et al. (2006, 2007) revealed the presence of a remarkable activation in hemocytes due to a sublethal concentration of plant treatment and mol- 
luscicidal compound. They attributed the degenerative changes of hemocytes cellular organelles to a direct toxic effect of these molluscicidal drugs. Further, the continuous exposure to sub-lethal concentrations of artemether caused an increase in glycogen content in hemocytes causing them to increase in size by increasing the time of exposure as reported by Mossalem et al. (2013).

Despite the promising molluscicidal activity of miltefosine, studies show administration results in severe side effects, miltefosine had broad biocide activity as well as it has been shown that miltefosine is a teratogenic agent and its use in the treatment as an anti-Leishmania medication has been associated with severe side effects (Bhattacharya et al., 2007; Eissa et al., 2011). On the contrary, the present study suggests that artemether can be effectively used as a safe plant origin molluscicide in the national $S$. mansoni control program due to some studies, do not show evidence of harm on non-target organisms. So, further research studies are warranted to evaluate the impact of artemether as safe molluscicidal and schistosomicidal agent (Piola et al., 2010; Elmorshedy et al et al., 2016).

\section{Conclusion}

Miltefosine and artemether have a toxic effect on $B$. alexandrina as they negatively affect immunological processes inducing degenerative changes and fragmentation of hemocytes. Consequently, tested drugs could be ranked as beneficial molluscicidal agents for the control program of schistosomiasis. However, artemether is cheaper to produce and safer for vector control. To further asses artemether in the control of schistosomiasis, it should be evaluated and tested for complete efficacy within the operational research bases for Schistosoma infection control.

\section{Acknowledgment}

This paper is part of Ph. D Thesis, sincere gratitude is expressed to Menuofia University, Faculty of Science, Biology Department, Egypt for the fruitful cooperation and continuous help throughout this work.

\section{Conflict of Interest}

The authors declare that there are no conflicts of interest

\section{References}

Abdul-Salam, J.M., Michelson, E.H. (1980): Biomphalaria glabrata amoebocytes, effect of Schistosoma mansoni infection on in vitro phagocytosis. J Invertebr Pathol., 35, 241-248. DOI: 10.1016/0022-2011(80)90157-3

ABOu-EL- NAGA, I.F. (2018): Towards elimination of schistosomiasis after 5000 years of endemicity in Egypt. Acta Trop. 181:112-121. DOI: 10.1016/j.actatropica.2018.02.005
AL-Kazzaz, M.A.N. (2014): Study of the efficacy of Nitazoxanide, Myrrh Total Oil and Mirazid in comparison with Praziquantel in experimental Schistosomiasis mansoni. M.Sc. University of Alexandria, Egypt

Bakry, F.A., Abdel Salam, H.A., Momeana, B., Hamdi, S.A.H. (2012): Influence of Atrazine and Roundup pesticides on biochemical and molecular aspects of Biomphalaria alexandrina snails. Pestic Biochem Physiol, 104: 9-18. DOI: 10.1016/j.pestbp.2012.05.012 Barcante, T.A., Barcante, J.M.P., FuJiwara, R.T., Lima, W.S. (2012): Analysis of circulating hemocytes from Biomphalaria glabrata following Angiostrongylus vasorum infection using flow cytometry. $J$. Parasitol. Res., 1-6. DOI: 10.1155/2012/314723

BERNARD, F. (2016): An update on hemocytes in Biomphalaria snails. J. Hematol. Oncol. Res., 2 (2): 20-27

Bertão, H.G., Ramos da Silva, A.R., Albuquerque, M., Radis-BaptistA. G.. De Azevedo Albuquerque, M. (2012 a): Ultrastructural analysis of miltefosine-induced surface membrane damage in adult Schistosoma mansoni BH strain worms. Parasitol. Res., 110: 2465-2473. DOI: 10.1007/s00436-011-2786-5

Bertão, H.G., Ramos da Silva, A.R., Radis-Baptista, G., de Azevedo AlbuQuerque, M. (2012 b): Miltefosine, an alkylphosphocholine originally developed as an antitumoral, is an effective compound against Schistosoma mansoni. Int. J. Pharm. Med. Biol. Sci., 1: 2278-5221

Bhattacharya, S.K., Sinha, P.K., Sundar, S., ThakuR, C.P., Jha, T.K., Pandey, K., Das, V.R., Kumar, N., Lal, C., Verma, N., Singh. V.P., Ranjan, A., Verma, R.B., Anders, G., Sindermann, H., Ganguly, N. K. (2007): Phase 4 trial of miltefosine for the treatment of Indian visceral leishmaniasis. J. Infect. Dis., 196(4): 591-598. DOI: 10.1086/519690

CAFrReY, C.R. (2007): Chemotherapy of schistosomiasis: present and future. Curr Opin Chem Biol, 11(4): 433-439. DOI: 10.1016/j. cbpa.2007.05.031

Cavalcanti, M.G.S.; Mendonça, A.M.B.; Duarte, G.R.; Barbosa, C.; De Castro, C., Alves, L.C., Brayner, F.A. (2012): Morphological characterization of hemocytes from Biomphalaria glabrata and Biomphalaria straminea. Micron, 43: 285-291. DOI: 10.1016/j. micron.2011.09.002

Cochennec-Laureau, N., Auffret, M., Renault, T., Langlade, A. (2003): Changes in circulating and tissue-ifiltrating hemocyte parameters of European flat oysters, Ostrea edulis, naturally infected with Bonamia ostreae. J. Invertebr. Pathol., 83 (1): 23-30. DOI: 10.1016/S0022-2011(03)00015-6

EIBL, H., Unger, C. (1990). Hexadecylphosphocholine a new and selective antitumor drug. Cancer Treat Rev., 17: 233-242. DOI: 10.1016/0305-7372(90)90053-i

Eissa, M.M., El-Azzouni, M.Z., Amer, E.I., Baddour, N.M. (2011): Miltefosine, a promising novel agent for schistosomiasis mansoni. Int J Parasitol., 41(2): 235-242. DOI: 10.1016/j.jpara.2010.09.010 EISSA, M.M., El-Moslemany, R.M., Ramadan, A.A., Amer, E.I., El-AzZOUNI, M.Z., EL-KHORDAGUI, L.K. (2015): Miltefosine lipid nanocapsules for single dose oral treatment of schistosomiasis mansoni: 
A Preclinical Study. PLoS One, 10: 22-29. DOI: 10.1371/journal. pone. 0141788

Eissa, S.H., Rizk, E.T., Abou-Shafey, A.E., Mona, M.H., Atlum, A. (2002): Toxicological effect of Euphorbia peplus water suspension on heamocytes of the fresh water snails, Biomphalaria alexandrina and Lanistus carinatus. Proc. LCBS, 2(2): 417-447

El Beshisish, S.N., El Bardicy, S., Tadros, M., Ayoub, M., Taman, A. (2018): Efficacy of artemisinin-naphthoquine phosphate against Schistosoma haematobium adult flukes: dose-effect relationship and tegumental alterations. J. Helminthol., 93(4): 513-518. DOI: 10.1017/S0022149X18000421

El-Faham, M.H., Eissa, M.M., Igetel J.E., Amer, E.I., Liddell, S., EL-Azzouni, M.Z., DoenHOF, M.J. (2017): Treatment of Schistosoma mansoni with miltefosine in vitro enhances serological recognition of defined worm surface antigens. PLoS Negl. Trop. Dis., 11(8): 1-26. DOI: 10.1371/journal.pntd.0005853

Elmorshedya, H., Tanner, M., Bergquist, R.N., Sharaf, S., Barakat, R. (2016): Prophylactic effect of artemether on human schistosomiasis mansoni among Egyptian children: A randomized controlled trial. Acta Trop., 158: 52-58. DOI: 10.1016/j.actatropica.2016.02.015

El-Sayed, K.A. Mohamed, M.B., Mossalem, H.S. (2011): Cryptostegia grandiflora affecting compatibility of Biomphalaria alexandrina and Biomphalaria galabrata to infection with Schistosoma mansoni with emphasis on some hematological effects. Aust J Basic Appl Sci, 5(12): 2210-2217

EL-SAYED, K.M. (2006): Effect of the plant Cupressus macrocarpa on some haematological and biochemical parameters of $B$. alexandrina snails. J. Egypt. Soc. Parasitol.; 36: 911- 924

EsmaElL, E.A. (2009): Biological and immunological studies on Biomphalaria alexandrina snails, the intermediate host of Schistosoma mansoni in Egypt. Ph.D. Thesis, Fac. Sci., Menufia Univ. Egypt GoldSTEIN, A. (1964): Biostatistics: An introductory text. Macmillan, New York, p. 51

Grimaud, J.A., Druget, M., Peyrol, S., Chevalier, D. (1980): Collagen immunotyping in human liver: Light and electron microscope study. J. Hist. Chem. Cytol., 28: 1145-1151

Ibrahim, A.M., Ahmed, A.K., Bakry, F.A., Abdel-Ghaffar, F. (2018): Hematological, physiological and genotoxicological effects of Match 5\% EC insecticide on Biomphalaria alexandrina snails Ecotoxicol. Ecotoxicol Environ Saf, 174: 1017-1022. DOI: 10.1016/j. ecoenv.2017.09.059

Kamel, E.G., Refaat, S.W., El- Dafrawy, S.M., Mohamed, A.H., Mossalem, H.S. (2006): The effect of Schistosoma mansoni infection on Biomphalaria alexandrina haematocytes at ultra-structural level. Proceeding of the $4^{\text {th }}$ International Conference of Biological Science (Zoology), p. 219

Kamel, E.G., RefaAt, S.W., El-Dafrawy, S.M., Mohamed, A.H., MosSALEM, H.S. (2007): Toxicological effect of certain plants and synthetic molluscicides on ultra-structural changes in hemocytes of Biomphalaria alexandrina. Egypt. J. Exper. Biol. (Zoo.), 3: 135-140 Le Clec'H, W., Anderson, T.J.C., Chevalier, F.D. (2016): Character- ization of hemolymph phenoloxidase activity in two Biomphalaria snail species and impact of Schistosoma mansoni infection. Parasit Vectors, 9: 32-38. DOI: 10.1186/s13071-016-1319-6

LIANG, Y.S., JOHN, B.I., BOYD, D.A. (1987): Laboratory cultivation of schistosome vector snails and maintenance of schistosome life cycles. In: Proceeding of the 1st Sino-American Symposium, 1: 34-48

LitCHField, J.T., WiLCOXON, F. (1949): A simplified method of evaluating dose effect experiments. J. Pharmacol. Exp. Therap., 96: 99-11113

LIU, R., Dong, H.F., JIANG, M.S. (2012): Artemisinin: the gifts from traditional Chinese medicine not only for malaria control but also for schistosomiasis control. Parasitol. Res., 110: 2071-2074

MicheLson, E.H. (1966): Specificity of hemolymph antigens in taxonomic discrimination of medically important snails. J. Parasitol., 52: 466-472

Madbouly, N.A., Ibraheem, R.S., El Deeb, S.O., El Amir, A.M. (2015): Effect of artemether on cytokine profile and egg induced pathology in murine Schistosomiasis mansoni. J. Advanced Res., 6: 851-857

Mohamed, A.Z., Abdel-Gawad, A.E. (2005): Effect of plant growth regulator (Mepiquat chloride) on circulating hemocytes and total plasma protein of Biomphalaria alexandrina snails. Egypt. J., 2001(44): 283- 303

Mossalem, H.S., IBRAHIM, A.M. (2019): The ameliorative potential of the ethanol extract of the plant Ocimum basilicum on Biomphalaria alexandrina snails exposed to the insecticide Bestacid . Egypt. J. Aqua. Bio. Fisheries., 23(1): 161-172

Mossalem, H.S.; Abdel-Hamid, H., El-Shinnawy, N.A. (2013): Impact of artemether on some histological and histochemical parameters in Biomphalaria alexandrina. Afr J Pharm Pharmacol, 7(31): 2220 2230

Oliveira, A.L.D., Levada, P.M., Zanotti-Magalhaes, E.M., MagalHÃES, L.A., RIBEIRO-PAES, J.T. (2010): Differences in the number of hemocytes in the snail host Biomphalaria tenagophila, resistant and susceptible to Schistosoma mansoni infection. Genet. Molecul. Res., 9 (4): 2436-2445

Piola, P., Nabasumba, C., Turyakira E., Dhorda, M., Lindegardh, N., Nyehangane, D., Snounou, G., Ashley, E.A., McGready, R., Nosten, F., GUERIN, P.J. (2010): Efficacy and safety of artemether-lumefantrine compared with quinine in pregnant women with uncomplicated Plasmodium falciparum malaria: an open-label, randomised, non-inferiority trial. Lancet Infect Dis., 10 (11): 762-769. DOI: 10.1016/S1473-3099(10)70202-4

Sumannatral, K., Sumannatral, A.B., Donthaisong, C., Arunsan, P., Thinkhamrop, K., TabsRipair, P., Welbat, J.U., Tangkawattana, S., Sotillo, J., Tesana, S. (2019): Hemocyte subpopulation changes in Bithynia snails infected with Opisthorchis viverrini in Thailand. bioRxiv, 1-18. DOI: 10.1101/536292

Van der Knaap, W. P., Sminia, T., Kroese, F. G., Dikkeboom, R. (1981): Elimination of bacteria from the circulation of the pond snail Lymnaea stagnalis. Dev Comp Immunol, 5: 21 
Weber, C.J., Calvopiña, J.H., Graef, K.M., Cathyryne, K.M., Dent, J. (2019): Platform for product-centered cross-sector partnerships for the Elimination of Schistosomiasis. Trop. Med. Infect. Dis., 4(11): 1-20

WHO (1965): Molluscicide screening and evaluation. Bull. WHO 33: $5675-5681$
Yoshino, T.P., DinguiRard, N., Kunert, J., HokKe, C.H. (2008): Molecular and functional characterization of a tandem-repeat galectin from the freshwater snail Biomphalaria glabrata, intermediate host of the human blood fluke Schistosoma mansoni. Gene, 411: 46-58 